\title{
Conceptual Engineering in Philosophy
}

\author{
Matti Eklund \\ matti.eklund@filosofi.uu.se
}

[Draft version. Final version published in Justin Khoo and Rachel Sterken (eds.), Routledge Handbook of Social and Political Philosophy of Language.]

\section{Introduction}

A good place to start when explaining and motivating what is variously called conceptual engineering, conceptual ethics, and ameliorative projects is the following passage from Nietzsche:

What dawns on philosophers last of all: they must no longer accept concepts as a gift, nor merely purify and polish them, but first make and create them, present them and make them convincing. Hitherto one has generally trusted one's concepts as if they were a wonderful dowry from some sort of wonderland: but they are, after all, the inheritance from our most remote, most foolish as well as most intelligent ancestors. [...] What is needed above all is an absolute skepticism toward all inherited concepts... ${ }^{1}$

Nietzsche puts this in characteristically dramatic terms. Put less dramatically, the basic idea is that there are concepts other than those we actually have and employ, and some of those concepts may be better suited for various purposes than our actual ones are. We can and should question our concepts, and consider whether there are better ones out there. And insofar as there are better ones out there, we should try to change our ways so that we come to employ the better concepts. There is then a philosophical project of critically assessing, and potentially revising or replacing, concepts.

I will later say more about how to understand the talk of concepts here. But there is one thing it is important to be clear on right away. The project is not just one of critically assessing our theories of various subject matters. It is one of critically assessing the concepts themselves, where "concepts" are the basic representational building-blocks of thought. Sometimes in ordinary language, "concept" is used loosely, in such a way that mere changes in theory trivially count as changing one's "concept". Here I will employ a concept/conception distinction, such that while such changes trivially count as changing one's conception of the matter at hand, it is a further question whether this counts as a revision of the concept itself. Maybe in some cases it does, but it is a theoretically contentious matter if and when it is so. ${ }^{2}$

This project described is not a new one. Philosophers have often (or always?) to some extent critically assessed concepts, coming up with their own technical concepts where the old concepts have not seemed up to the task, as well as revise and criticize existing concepts. Within the analytic philosophy tradition, Carnap (1950, ch. 1) and Quine (1960) both prominently stress explication. Within the continental tradition, theorists like Heidegger make up their own concepts for describing the world. Brandom (2002) describes Leibniz, Spinoza and Hegel as conceptual engineers. ${ }^{3}$ As displayed by the passage quoted above, conceptual engineering is a central theme in Nietzsche. And these are just a few examples. But what arguably is new is systematically studying conceptual engineering, where that involves finding features common to seemingly quite disparate conceptual engineering projects and delving into general questions raised by such projects. For example, it can be claimed that the revision and replacement of concepts isn't always self-conscious, and by making

\footnotetext{
${ }^{1}$ Nietzsche (1901/68), section 409.

${ }^{2}$ On concept/conception distinctions similar to that drawn here, see, e.g., Rawls (1971), Higginbotham (1998), and Ezcurdia (1998).

${ }^{3}$ Brandom (2002), p. 116.
} 
explicit what we are doing and being more systematic we can do it better; and by comparing conceptual engineering projects from different parts of philosophy we can shed useful light on them. Much of the discussion below will concern the study of conceptual engineering - the newer development - rather than the activity of conceptual engineering itself. There has been a flurry of work on conceptual engineering in recent years. There is too much to usefully list or summarize, but among more important work can be mentioned Burgess and Plunkett's pioneering articles (2013) and (2013a), Cappelen (2018), Scharp (2013), the essays collected in Haslanger (2012), and the essays collected in Burgess, Cappelen and Plunkett (forthcoming).

In the discussion below I will keep returning to paradigm examples of conceptual engineering from the recent literature: Sally Haslanger on the concept WOMAN and Kevin Scharp on the concept TRUTH. ${ }^{4}$ This is partly for the sake of convenience. These examples are often discussed, and well-known. But it should be kept in mind that these are just some of many examples.

Different labels have recently been used for the kind of project I will describe - "conceptual engineering", "conceptual ethics", and "ameliorative project". For the purposes of my discussion here I will not be concerned with differences between these labels, even though distinctions can be drawn. ${ }^{5}$

\section{Examples}

Here, in brief, are Haslanger's and Scharp's ideas.

Haslanger thinks that we should replace the actually used concept WOMAN by the following one:

$\mathrm{S}$ is a woman iff $\mathrm{S}$ is systematically subordinated along some dimension (economic, political, legal, social, etc.), and $\mathrm{S}$ is "marked" as a target for this treatment by observed or imagined bodily features presumed to be evidence of a female's biological role in reproduction. ${ }^{6}$

The motivation, put briefly, is that there is oppression of the kind described, and employing a concept that captures that is a way of raising the fact to salience, in a way that helps combat this oppression. I should perhaps stress that Haslanger at least sometimes clearly speaks of changing our conception of the concept WOMAN rather than changing the concept WOMAN itself: she emphasizes that how the concept seems to us ("the manifest concept") differs from how the concept really works ("the operative concept"). ${ }^{7}$ However, in the discussion to follow my focus will be on Haslanger qua conceptual engineer.

Scharp argues that our concept TRUTH is in a certain sense inconsistent, in a way that comes to light through semantic paradoxes such as the liar paradox. He then goes on to argue that because the concept TRUTH is inconsistent we should replace it, and he proposes as replacement a pair of concepts which together can do the work that, in theoretical contexts, we want the concept TRUTH to do for us. ${ }^{8}$ The differences between Haslanger's and Scharp's projects are stark, which is one reason for juxtaposing them in the context of discussing conceptual engineering. The concepts they focus on are obviously very different, and the considerations they bring to bear are also different.

\footnotetext{
${ }^{4}$ See primarily Haslanger (2000) and (forthcoming (a)), and Scharp (2013).

5 The expression "conceptual engineering" was apparently first used by Creath (1991). Other early uses are found in Blackburn (1999) and Brandom (2001). "Ameliorative project" is Haslanger's expression (in earlier work she used "analytic" rather than "ameliorative"). "Conceptual ethics" is the preferred label of Burgess and Plunkett (2013, 2013a).

${ }^{6}$ Haslanger (2000), p. 39. In her more recent (forthcoming (a)), Haslanger includes a relativization to contexts.

7 See Haslanger (2006), p. 110) and Haslanger (2012) p. 15. For discussion, see section 7.6 of Cappelen (2018).

${ }^{8}$ Scharp develops the idea in many places, but see primarily his (2013).
} 


\section{Preliminary remarks}

Armed with these very brief sketches of two prominent conceptual engineering projects, let me now address some questions which likely arise.

What are concepts? There is no uncontroversial answer to this question. At a first stab, they are the basic building blocks of thoughts, or of the thoughts that have something like linguistic structure. Perhaps one can say that concepts are the meanings of (subsentential) expressions. ${ }^{9}$ Needless to say, these characterizations carry theoretical baggage, and can be questioned. And even if the latter gloss can be defended, it is only moderately helpful, for example because there are different theories of what meanings are. One important distinction between views on meaning is that between views on the meaning of an expression is its intension, and views on which meaning is something more finegrained which determines its intension. Some authors in the conceptual engineering literature, e.g. Scharp, approach meaning and concepts via the question of what it is to be competent with an expression or concept. One might for example say that to be competent with a concept is to be disposed to accept such-and-such principles involving it, or (Scharp's preferred view) entitled to accept such-and-such governing principles it. This approach allows for meanings or concepts to be more fine-grained than intensions: for different sets of governing principles can correspond to one and the same intension.

While as it is often discussed conceptual engineering concerns, precisely, concepts, this need not be taken very seriously. ${ }^{10}$ First, somewhat more neutrally one can speak of representational devices. And some may prefer to speak of words and their reference and extension, instead of speaking of concepts. Instead of asking which concepts we should have, one can ask which things we should have words for. Second, at least for some purposes one might sidestep representational devices altogether and instead directly speak in terms of that which such devices refer to or ascribe. Instead of saying, for example, "we should employ the concept GREEN and not the concept GRUE" one can say: we should focus on the property greenness and not the property grueness. (Note that questions analogous to those of the individuation of concepts arise also in the case of properties: can there be two properties which are necessarily co-instantiated yet are distinct?) I say "for some purposes", both because there are not always corresponding worldly items (consider e.g. non-representational language and thought), and because sometimes what is at issue is not just what is represented but the manner in which it is represented.

Who are "we"? In the above characterizations of Haslanger's and Scharp's projects, I have spoken of what "we" should do. But who are "we" here? Answers can differ depending on the project concerned. Scharp is at pains to emphasize that his proposal that the concept TRUTH be replaced concerns only what certain kinds of theorists should do, in the context of their theoretical investigations. He is not at all concerned with everyday uses of the concept. By contrast, Haslanger is at least in part concerned with what concept WOMAN should be used more broadly, even if her focus is on feminist theorizing.

Retail or wholesale? The previous remarks are relevant also another natural question. Is the conceptual replacement or revision supposed to be retail - the proposal concerns only some uses of the concept - or wholesale - concern all uses of the concept? As already the above remarks on

\footnotetext{
${ }^{9}$ Where presumably one should specify: expressions that are not context-sensitive. Other questions may be asked about this gloss. Should we here include all kinds of subsentential expressions - including things like "on" and "to"? It may sound odd to speak of "the concept to"; on the other hand, "to" makes a distinctive contribution to thoughts and one can evaluate this contribution as well as others, so the conceptual engineering questions arise here too.

${ }^{10}$ For example, Cappelen (2018) expresses skepticism about concepts while defending conceptual engineering.
} 
Scharp indicate, Scharp's revision is clearly retail. He only means to address the question of which truth concept should be employed in certain theoretical contexts. Whereas I don't see Haslanger committing herself to a wholesale view, her view is at least closer to such a view.

What is it for a concept to be better than, or preferable to, another? First, it can be claimed that there are some possible outright defects that a concept can have and that a concept is generally better than another if the former is defect-free and the latter has one of these defects. Among such defects can be inconsistency and indeterminacy. Another defect might be that the use of the concept in some sense presupposes the truth of a false view, for example a false normative view. ${ }^{11}$ (Perhaps the use of a concept expressed by a racial slur presupposes the truth of some false racist belief. Perhaps the use of concepts like those expressed by "promiscuous" or "chaste" presuppose the truth of certain false moral beliefs. ${ }^{12}$ )

Second, there can be reasons that are more specific to the task at hand. A concept can be better than another in the sense that employing the former is more likely to generate positive social change. $A$ concept can be better than another because it better tracks what is explanatorily powerful or inductively useful. A concept can be better than another simply because it is easier for creatures like us to work with. And so on. There will be many relevant dimensions along with a concept can be better than another.

What is it to revise a concept? Sometimes in discussions of conceptual engineering, the focus is on revising a particular concept: before the changes the concept has a particular intension and maybe some particular governing principles, and after the changes the concept has a different intension and maybe different governing principles. Such talk invites questions about what changes a concept can undergo and still remain the same concept. Can a concept really survive a change in intension or governing principles? My own view is that such questions are not very important. There are simply different ways of individuating concepts, and so long as we are clear on which method of individuation we choose, nothing of interest hinges on the choice. If we are strict about concept identity then what some people are speak of as one concept undergoing changes is in fact the replacement of a concept by another, related one. I myself gravitate toward such strict individuation; but I do not see my favoring that as my taking a stance on a theoretically significant issue.

At any rate, not all changes to our overall conceptual repertoire in the spirit of the Nietzsche passage above would be instances of the kind of concept change just discussed, even for those happy with the idea that there is such concept change. Sometimes there is arguably genuine conceptual innovation, where a concept is added such that there is no earlier counterpart of the concept. Sometimes there may be cause for simple concept deletion: some concept is dropped, and no concept is added specifically to replace it.

Having and employing concepts. Independently of the issues of conceptual change mentioned above there are good questions about what it is to have and to employ a concept. Consider the concept which Haslanger proposes to identify as the concept WOMAN. There is a sense in which we had this concept even before Haslanger entered the scene. We had the concepts SUBORDINATION, etc., and we grasped the relevant means of forming complex concepts from simpler ones. So in what sense is

\footnotetext{
11 In an intuitive sense of "presupposes". The suggestion is not necessarily that this is presupposition in any of the technical senses standardly employed in philosophy of language and linguistics.

12 Needless to say, these are just brief illustrations. There are alternative views on the examples mentioned. For example, maybe the concept expressed by a slur word is the same as that expressed by the corresponding neutral word: the racism expressed through the use of a racial slur is expressed through other mechanisms than through the concept used. (Maybe - see, e.g., Nunberg (2018) and Bolinger (2017) - the use conveys racism because it is common knowledge that this is the racists' preferred word.)
} 
what Haslanger proposes a conceptual novelty? There are distinctions to be drawn here. The following gestures towards what one relevant distinction might be: although we had all the constituent concepts and grasped their mode of combination, and so in a sense had the complex concept all along, we have not so far actually employed these complex concept, and starting to employ it is a change in our practices. Needless to say, more can be said about how to draw the relevant distinction.

These distinctions are relevant to some stated motivations for conceptual engineering. Burgess and Plunkett (2013) say that one central motivation for conceptual engineering (or "conceptual ethics", as they put it) is that which concepts we have "fixes what thoughts we can think" - "our conceptual repertoire determines not only what beliefs we can have but also what hypotheses we can entertain, what desires we can form, what plans we can make on the basis of such mental states, and accordingly constrains what we can hope to accomplish in the world". But to the extent that the engineering concerns which concepts we more easily or readily employ, and not which concepts we have, some of this rhetoric should arguably be tempered. Already the point that some concepts are more easily and readily used than others is relevant - there may be good reasons to modify what concepts are easily and readily used - but it shouldn't be conflated with points about which concepts we have in the first place.

\section{Concepts and words}

Above I mentioned that instead of asking which concepts we should employ, one can ask about reference and extension, and ask which things we should have words for. Now, even two theorists who agree about which concepts to employ and about things we should have words for can sharply disagree about which words should be used for what. It is important to distinguish between different kinds of questions that arise. Some questions concern what to have labels and descriptions for; others concern what labels and descriptions to use. While questions of the former kind arguably are more central to conceptual engineering, questions of the latter kind also come up. ${ }^{13}$

Cappelen (2018) prominently discusses what he calls lexical effects in connection with conceptual engineering. Examples he mentions to illustrate the phenomenon, are that of naming a child 'Hitler', the use and importance of brand names, and the conception of slurs given which their slurring effects are due not to semantic features but simply due to which labels are being used. ${ }^{14}$

Especially in connection with Haslanger's project, the question has come up of whether one should retain the old word for the revised concept. Should we use "woman" for the concept that Haslanger devises or not? Haslanger herself says,

...if our goal is to identify a concept that serves our broader purposes, then the question of terminology is primarily a pragmatic and sometimes a political one: should we employ the terms of ordinary discourse to refer to our theoretical categories, or instead make up new terms? The issue of terminological appropriation is especially important, and especially sensitive, when the terms in question designate categories of social identity such as 'race' and 'gender'.

...by appropriating the everyday terminology of race and gender, the analyses I've offered invite us to acknowledge the force of oppressive systems in framing our personal and political identities. Each of us has some investment in our race and gender: I am a White woman. On my accounts [of race and gender], this claim locates me within social systems that in some respects privilege and in some respects subordinate me. Because gender and racial inequality are not simply a matter of

\footnotetext{
13 In addition to what is discussed in the main text, see, e.g., Sterken (forthcoming).

${ }^{14}$ Cappelen (2018), p. $123 \mathrm{f}$.
} 
public policy but implicate each of us at the heart of our self-understandings, the terminological shift calls us to reconsider who we think we are. ${ }^{15}$

No doubt terminology is important, for example in cases like those of race and gender. But there is still something that might seem problematic about what Haslanger says: "Each of us has some investment in our race and gender: I am a White woman. On my accounts, this claim locates me within social systems that in some respects privilege and in some respects subordinate me". Here one starts with a particular claim, in the case of Haslanger that expressed by the sentence "I am a white woman". What are claims? It is natural to identify claims as propositions. If I say "snow is white" and a German speaker says "Schnee ist weiss" we are making the same claim; that is, we assert the same proposition. If claims are propositions, then what Haslanger speaks of is what a particular proposition does on her accounts of gender and race. But a different reaction is to say that before Haslanger's proposed conceptual and terminological revision, "I am a white woman" expresses one proposition and after the revision has been implemented, it expresses another. One may then be concerned that there is no one proposition such that we are invested in that proposition pre-revision, and that then that very proposition is such that given a revisionary account of $i t$, that proposition locates the speaker in a social system in the way described. ${ }^{16}$

Some prominent criticisms of Haslanger have focused on terminology (see, e.g., Katharine Jenkins (2016)). Critics have fastened on the fact that Haslanger's definition of "woman" seems to exclude trans women, and they have objected to this consequence of the view. This criticism, even if on target, has to do primarily with the label associated with the concept. If Haslanger instead had used a made-up label for the concept she characterizes, this would not have been an issue - at least not so long as Haslanger also allowed for another concept which would be labeled "woman", under which trans women would fall. ${ }^{17}$

Jenkins proposes a revision of the concept WOMAN such that in the sense of the proposed concept WOMAN, trans women are "women". This is meant as an improvement over Haslanger's proposal. But one may worry that insofar the proposition regarding trans women that one seeks to defend is that trans woman indeed are women, one does not defend that proposition by proposing a new concept WOMAN such that "trans women are women" expresses a true proposition when "women" expresses the new concept. To believe otherwise is tantamount to think that if we call a dog's tail a leg, a dog will have five legs. To defend the original claim one must defend that trans women are women in the ordinary, pre-revision sense of "woman". Maybe that can be done - I am not weighing in on that issue - but concept revision does not make that case. ${ }^{18}$

\section{Doubts about conceptual engineering as a philosophical project}

When motivating attention to conceptual engineering, Plunkett and Cappelen (forthcoming) stress the ubiquity of concept use. Whatever cognitive activities we engage in, we employ concepts, and which concepts we employ matters to how we perform the activity in question. Plunkett and

\footnotetext{
15 Haslanger (2000), p 47.

${ }^{16}$ Above I mentioned, only to set aside, the possibility of different individuations of concepts. There are parallel questions about the individuations of propositions. The formulation in the text presupposes that one and the same proposition cannot undergo changes in content. The underlying concern can be expressed even given a different individuation of propositions. Wasn't what we were invested in the proposition with the content it had? (As opposed to: the proposition itself, whatever its content might come to be.)

${ }_{17}$ Haslanger does stress that the question of the usefulness of the concept she describes and the question of whether to use "woman" for that concept are independent questions. See, e.g., Haslanger (2000, p. 47) and (forthcoming a).

${ }^{18}$ Again (see previous footnote) the formulation in the text presupposes that one and the same proposition cannot undergo changes in content. Again the underlying concern can be expressed even given a different individuation of propositions.
} 
Cappelen say that facts such as these "help underscore the potential significance of philosophical work done on conceptual engineering". ${ }^{19}$ Now, they do say "potential", but it is anyway important to stress that the central importance of concepts by no means immediately shows that there is a significant philosophical project of studying conceptual engineering. In this section I bring up three possible reasons for skepticism.

(1) Not unified enough? Even if individual projects of conceptual engineering, such as Haslanger's and Scharp's, are of interest, one can think that these projects are dissimilar, in such a way that nothing is gained by treating these projects as parts of a bigger, unified project, conceptual engineering. The projects may be no more unified than the areas of philosophy of gender and race on the one hand and philosophy of logic on the other are unified. To be sure, in both cases, we talk about revising and replacing concepts, but the means of assessing the proposals are so different that there is no unified philosophical project there. There are of course general questions about concepts and their identity conditions (as well as about the legitimacy of concept talk in the first place), but these questions are so general that they have nothing to do with conceptual engineering per se. Plunkett and Cappelen suggest that the importance of questions about which concepts we use means that "work done on conceptual engineering" may be significant. But, relating back to the distinction drawn early on, even if individual projects involving engineering concepts may be significant, the general study of conceptual engineering is a different thing, and it is in regards to that study that one may be concerned about lack of unity.

(2) Not philosophical enough? A second cause for doubt about conceptual engineering as a philosophical project concerns how philosophical the project properly is. Might not the question of how good or bad a concept is be a question of the actual consequences of employing it, as compared to employing other concepts - an empirical matter? And are not questions about how a concept is best implemented questions to be resolved empirically? Perhaps in each case one can to some extent speculate reasonably from the armchair; still, such speculation is no substitute for empirical work. It may be silly to police how the label "philosophy" should be used, but it still stands that the typical training of philosophers makes philosophers better equipped to address certain questions than to address others.

Which concept WOMAN is best for particular feminist political purposes - whether we think of a concept WOMAN for working feminist theorists to use or we think of a concept WOMAN for the society at large to use - seems an eminently empirical matter. A project like Scharp's can seem more nonempirical in nature, for the problem identified in the case of the concept TRUTH is inconsistency, and it can be thought that empirical research is not needed to establish that inconsistency is a defect. But first, empirical work could still be needed to properly investigate which replacement concept or concepts are the most useful to employ. And second, while inconsistency certainly sounds like a defect, whether it is depends on what it is for a concept to be inconsistent - and there are different accounts of that. The way Scharp characterizes this, a concept is inconsistent exactly if competence with the concept entails being (defeasibly) entitled to accept principles which in fact lead to inconsistency. ${ }^{20} \mathrm{It}$ is not obvious that this is cause for replacement. What is so bad if I employ a concept like that? My employing such a concept does not in any way mean that I believe contradictions, or am disposed to believe contradictions, or am in some sense committed to believing contradictions. But if the inconsistency of a concept is not generally a defect, the question of whether it is in a particular instance can be thought to turn on whether the inconsistency in fact leads to problems, and that is again an empirical issue. I will return to this below.

\footnotetext{
19 Plunkett and Cappelen (forthcoming).

${ }^{20}$ Scharp (2013), p. 46.
} 
A different kind of reason for thinking that questions about what concepts should be revised are at bottom empirical is that much of what we use words to convey - and arguably much of what we use concepts to think - goes beyond what is literally expressed by those words and what is strictly part of the contents of those concepts. But then much of a word's or concept's value or disvalue can have to do with what else the word or concept is being used to do; and the question of what else it is used to do is empirical.

Maybe some conceptual engineering projects are more philosophical in nature. What makes Haslanger's and Scharp's motivations for conceptual engineering seem empirical is the focus on purported practical benefits of a given kind. A completely different kind of "conceptual engineering" project focuses not on practical matters but on what a kind of ideal language would be like - the language our theory is stated in at the end of inquiry, or the language that most perspicuously represents what reality is fundamentally like. Such projects may be more philosophical, for an obvious reason: designing such a language is not very different from the project of considering what reality is fundamentally like, and that latter question is one where philosophy is traditionally seen as having contributions to make. ${ }^{21}$

(3) No distinct subject matter? A third reason for doubt is that conceptual engineering is not a distinct subject matter. I already alluded to the fact that some relevant questions, about concepts and their identity conditions, are more general and do not concern conceptual engineering per se. Also some other questions that have come up in connection with conceptual engineering seem clearly just to be applications of more general points. For example, Simion (2018) argues that it is not permissible to revise concepts when there is 'epistemic loss', and she says that what she identifies is a wrong-kind-of-reasons problem familiar from elsewhere in the literature. ${ }^{22}$ Beliefs are to be assessed on their own, epistemic terms rather than in terms of all-things-considered considerations. Whatever the fate of Simion's argument, it is clear that it turns on how epistemic value relates to other sorts of normative considerations. ${ }^{23}$

\section{Conceptual engineering questions}

One way for the friend of conceptual engineering to combat skepticism about conceptual engineering as a philosophical project is to, constructively, point to some philosophical questions that concern conceptual engineering as a general philosophical project, and emphasize the significance of these questions. Here are some questions she might point to.

First, there is what has come to be called Strawson's challenge. ${ }^{24}$ This is discussed in, e.g., Prinzing (2017), Cappelen (2018), and Dutilh Novaes (forthcoming). Here is Cappelen's (2018) statement of the challenge:

Change of extension and intension (and so also change of sense, if you believe in those) is a change of topic, so [projects involving conceptual revisions] are bound to fail. Even if the revisions

\footnotetext{
${ }^{21}$ If we focus on the ideal scenario kind of case, another concern arises. Ought we not, at the ideal stage, to employ all concepts? At the end of inquiry we will want to have catalogued all truths, so if there are any truths at all that we fail to include, even fairly useless ones, we have not done as well as we could. In an idealized scenario we do not need to choose which among all the truths to focus on. Dever (forthcoming) argues for "conceptual maximalism", the view that we should employ all concepts; and, relatedly, for the view that we should work in "all languages". He realizes that we of course cannot do everything at once, so that there will be choices about what to focus on here and now. The way I see it, his global maximalism is then a view about a kind of ideal theorizing.

22 See, e.g., Rabinowicz and Rønnow-Rasmussen (2004).

${ }^{23}$ For discussion of Simion's argument, see Catapang Podosky (forthcoming).

${ }^{24}$ So called because it arguably echoes themes from Strawson's (1963) discussion of Carnap.
} 
succeed, they do not provide us with a better way to talk about what we were talking about; they simply change the topic. ${ }^{25}$

The concern is this. When we engage in conceptually engineering, we revise or replace concepts, and when we do so, we change the topic. But if we change the topic, then we no longer address the questions we originally were asking.

This is a general concern, applying equally to projects like Haslanger's and to projects like Scharp's. And it applies specifically to conceptual engineering, and isn't equally an issue for all theories in some sense about concepts, for it concerns precisely conceptual change. Cappelen's own response to the challenge involves defending a liberal notion of sameness of topic given which the topic is not changed. My own view on the challenge is that it is a non-issue. Whether it matters that the topic is changed depends on what our purposes are. If the concept revision is supposed to be justified by moral and political aims, then the chief question is whether those aims are better served by the new concept. If it is supposed to be justified by concern about explanatory and predictive success then the chief question is whether the new concept better serves that aim. Change of topic is a bad thing exactly insofar as, among other purposes we do or should have, there is the purpose of saying something about the old topic. But why should that always be among our purposes? Maybe we are not answering the original questions asked. But maybe the old questions weren't the right ones to ask anyway.

When motivating Strawson's challenge, Cappelen quotes, among others, Peter Ludlow (2005). What Ludlow actually says is: "[F]irst, and most obviously, any investigation into the nature of knowledge which did not conform to some significant degree with the semantics of the term 'knows' would simply be missing the point." ${ }^{26}$ Of course, if an investigation really is an investigation into the nature of knowledge (to stick with the case Ludlow focuses on), then we had better make sure we not stray from the target, the nature of knowledge. But a conceptual engineer concerned with knowledge could well say: what we ought to be concerned with, e.g. for the purposes of the relevant kind of epistemic evaluation, isn't knowledge but knowledge*. Then we ought not tie our investigation to the nature of knowledge but should shift the focus to the nature of knowledge* - at least so long as what we are interested in is what is best for the purpose of the relevant kind of epistemic evaluation. ${ }^{27}$

Second, recently (e.g. in Cappelen (2018), Koch (2018)) there has been some work on whether externalism, the view that the meaning of an expression as used by a speaker is constitutively determined in part by factors outside her, makes the project of actively working for conceptual change unfeasible: speakers have no control over conceptual change. This is a question of the compatibility of externalism with conceptual engineering. Of potential relevance here is that there are different kinds of externalism. Sometimes externalists stress the causal environment; sometimes it is the speaker's social environment that matters. Some externalists think some facts about meaning and content can be determined by future facts. Some externalists may think it is in the nature of meaning and content that it is determined in part by external factors where others may hold the more moderate view that it is in virtue of our implicit decisions and conventions that

\footnotetext{
${ }^{25}$ Cappelen (2018), p. 100.

${ }^{26}$ Ludlow 2005, p. 13; quoted in Cappelen (2018), p. 98.

27 In fact, even Strawson himself says, "[I]t seems prima facie evident that to offer formal explanations [i.e. Carnap-style explications] of key terms of scientific theories to one who seeks philosophical illumination of essential concepts of non-scientific discourse, is to do something utterly irrelevant - is a sheer misunderstanding" (1963, p. 505). Notice the relativization: the point essentially concerns what serves the purposes of someone who "seeks philosophical illumination of essential concepts of non-scientific discourse". What if one simply does not have that aim?
} 
external factors turn out to be relevant (we have decided to let our concept WATER work in such a way that with respect to every possible world, it is true of the actual watery stuff. The problems caused by externalism are at least more dramatic given the first kind of view.

Again, is it not largely an empirical issue to what extent externalism presents problems? One possibility is that, for example, persuasive arguments for conceptual revision can have such impact on the community that even by externalist standards conceptual change is taking place, and since argumentation is the driving force, this is under our control. How likely it is that argumentation has that effect is an empirical issue. ${ }^{28}$

Third, maybe, despite differences between conceptual engineering projects, there can be some informative principles governing how to evaluate concepts, and when to revise or replace concepts. For example, Alexis Burgess and David Plunkett have discussed the question of under what conditions a given concept can itself be legitimately be used in discussions of whether that very concept should be replaced or abandoned. ${ }^{29}$ If a concept is employed in an argument for retaining that concept, that may be seen as problematic: it is, so to speak, the concept itself that vouches for its innocence (or that is the concern). And if the concept is employed in an argument to the effect that the concept ought to be revised or replaced, that too might be seen as a problem: if the concept itself cannot be trusted, why should an argument that employs the concept? I am stating these questions only briefly. As stated they face the concern that a lot hinges on the specific supposed reasons for why the concept should be replaced, and what the argument for replacement looks like. For example, if what is at issue is only that some other concept is more explanatory than C or the fact that $\mathrm{C}$ is more vague than relevant alternatives, there is no immediate reason at all to suspect that there is something amiss with using $\mathrm{C}$ in an argument that $\mathrm{C}$ should be retained.

Fourth, there are questions about the limits of conceptual engineering. In his (2011), David Chalmers introduced the notion of a bedrock concept. As Cappelen (2018) discusses, this can be thought to have implications regarding conceptual engineering. The main topic of Chalmers (2011) is that of verbal disputes. As Chalmers notes, a strategy for deciding whether a given dispute is verbal is to state the dispute with the key term replaced by other terms, and see if the dispute remains. If the dispute goes away, it was verbal. If it remains, the dispute wasn't verbal. But having stated this "method of elimination", Chalmers notes an apparent limitation: in some cases it seems that the dispute cannot be faithfully restated without the use of the key term. Here he illustrates this in the case of moral disputes:

...we can bar 'ought' and introduce 'ought ${ }_{1}$ ' and 'ought ${ }_{2}$, which are stipulated to apply to acts with the deontological and the consequence property respectively. Is there a residual disagreement now?

As we proceed, the disagreement gets harder and harder to state. It is plausible that once all moral terms are gone, no disagreement can be stated. We might agree on all the nonmoral properties of the relevant actions but still disagree on whether it is right.

In the case of 'semantics', 'physicalism', and so on, this situation suggested a verbal dispute. Should we likewise diagnose a verbal dispute here? Intuitively, the answer is no. For all we have said, moral disputes are substantive disputes. Instead, we have simply exhausted the relevant vocabulary. It appears that at a certain point (perhaps once we have fixed on the appropriate

\footnotetext{
${ }^{28}$ Cappelen (2018, p. 82) also points out that problems arise even given internalism. We need not have control over what concepts we employ even given internalism. As in the case of externalism, it is an empirical matter to what extent we do have such control. It is not a given that we have control over the internal factors that the internalist focuses on.

${ }^{29}$ See Burgess and Plunkett (2013a), Burgess (2014), and Burgess (forthcoming).
} 
moral "ought"), we have reached bedrock: a substantive dispute involving a concept so basic that there is no hope of clarifying the dispute in more basic terms. ${ }^{30}$

Chalmers characterizes a "bedrock dispute" as "a substantive dispute for which no underlying dispute can be found by the method of elimination", and "bedrock expressions" are such that "some disputes are bedrock with respect to those expressions" (where "a dispute is bedrock with respect to $E$ when the dispute is substantive and there is no dispute not involving $E$ (and analogous in other respects) that underlies the original dispute").

There is much to say about what Chalmers says about bedrock. Here I confine myself to discussing relevance to conceptual engineering. Cappelen (2018) brings up Chalmers' notion of bedrock as relevant to conceptual engineering. He says that in his terminology, bedrock expressions are "expressions that cannot be engineered"; they are "conceptual foundations where there's no option of moving to a neighboring property". ${ }^{31}$ He then goes on to say that he disagrees with Chalmers about whether there are any bedrock expressions. I think Cappelen at least overstates the relevance to conceptual engineering. If $\mathrm{E}$ is a bedrock expression then one cannot eliminate the expression without a sense of loss: one cannot faithfully state what was at issue in theses involving $E$ when $E$ is not used. But one can certainly still in principle argue that even so, E should be eliminated or revised. The loss in question is a loss we can and should live with.

I have myself presented arguments regarding the limits of conceptual engineering, both suggesting that it becomes problematic to pose the conceptual engineer's questions when it comes to foundationally important normative concepts, and that there is a sense in which there are no alternatives to the notions of truth and existence - there are, in a certain sense, no alternative suitably TRUTH-like and EXISTENCE-like concepts. ${ }^{32}$ In brief, the considerations are these. When it comes to truth, the question is what it would be for a community to employ a concept which plays the role of our concept TRUTH but still is not coextensive with it. In the case of existence, the point is that differences in what EXISTENCE-like concept a community uses has ripple effects for the rest of that community's system of concepts, so that selectively replacing EXISTENCE by some other EXISTENCE-like concept is not possible. The case of foundationally important normative concepts is the one I have discussed in the most detail - see my book Eklund (2017) - and there the point is, in brief, that it is unclear what the conceptual engineering could reasonably concern. When we ask, "which OUGHT-like concept ought we to use, our actual concept OUGHT, or an alternative?", the obvious problem with the question is that the answer to the question will likely depend on what concept we use the "ought" to express.

Cappelen brings up my arguments alongside those of Chalmers as arguments to the effect that some concepts cannot be engineered. Without getting into detail regarding those arguments of mine and their worth, let me just emphasize that the same sorts of remarks apply to them as applied to Chalmers' arguments. Even if my arguments are completely correct as far as they go, and even if they do establish certain limits to conceptual engineering, certain forms of conceptual engineering are possible also when it comes to these concepts. There are still questions about whether one should employ a TRUTH-like or EXISTENCE-like concept at all. And in the case of normative concepts, my argument does not even purport to establish that we could not replace OUGHT by some alternative, OUGHT*: the problem rather has to do with what kind of comparison we are engaged in when proposing the replacement.

\section{Different conceptions of meaning and content}

\footnotetext{
${ }^{30}$ Chalmers (2011), p. 543.

${ }^{31}$ Cappelen (2018), p. 194.

${ }^{32}$ See, e.g., Eklund (2015), (2017) and (forthcoming).
} 
Here is a rough distinction between two different ways of looking at concepts and meaning. On a referentialist view, there is nothing more to (descriptive) meaning than intensions. If two expressions have the same intension then they have the same meaning. On an inferentialist view, some inferences are in part and somehow constitutive of concepts or meaning. (The terminology is from Williamson (2009).) The inferentialist cuts things more finely than the referentialist, for two expressions can have the same intension while being associated with different constitutive inferences. In the conceptual engineering discussion, Cappelen and Haslanger are referentialists. ${ }^{33}$ Cappelen even expresses doubts about the propriety of talk about concepts. Scharp is a prominent inferentialist (and I myself am attracted to inferentialism). ${ }^{34}$

These differences in turn generate differences in how to think of conceptual engineering. For the referentialist, the engineering has to do with changes in what we talk about (we shift from using an expression with one intension to using that or another expression with another intension), and with things that aren't strictly on the meaning or content side at all - what Cappelen calls lexical effects. For the inferentialist, there are more options: the inferentialist can also focus on what inferences are constitutive of an expression's meaning or a concept. Whether one spells out constitutivity in psychological or epistemic terms, there is a possibility that constitutive inferences are not always necessarily truth-preserving, and they may even engender contradiction. Inferences we are disposed to accept may not be truth-preserving. Inferences we are entitled to make may not be truthpreserving. Both Scharp and myself hold that the liar paradox is generated by constitutive principles (together with undeniable truths). It is natural to think that when a concept's constitutive principles are false or contradictory, the concepts needs to be revised or replaced. ${ }^{35}$

\footnotetext{
${ }^{33}$ See, e.g., Haslanger (forthcoming (a)) and Cappelen (2018). Haslanger emphasizes that the content of a concept is a "partition of logical space", and genuine conceptual revision amounts to changing what partition of logical space the term or concept represents" [reference]. (Haslanger contrasts genuine revision - what she calls informational or semantic amelioration - with epistemic amelioration, where we simply "improve our understanding of the informational content of the concept" [reference]. She goes on to emphasize:
}

There are no "core commitments" associated with words that cannot be overturned or negotiated. Although in some sense we represent the world - propositions are abstract entities that carry information and are, to that extent, representational - the "mode of representation" is not part of the informational content of what we say and think. [reference]

In her forthcoming (b), Haslanger speaks of concepts as "clusters of dispositions" [reference], and distinguishes concepts from their contents. But at the same time, she - both in that work and other works - expresses skepticism about the idea that all users of a given concept have the same dispositions. For example, in her forthcoming (b), she says, "possession of the concept may occur by virtue of different cognitive mechanisms and give rise to very different dispositions in different individuals" [reference]. The claims seem hard to square with each other. It is tempting to assume that her real view is only that to have some suitable cluster of dispositions (and this is also how she puts it in her forthcoming (a)). But maybe the idea is that even if different individuals possessing the concept have different dispositions, "cluster of dispositions" is so general that the individuals count as possessing the same disposition cluster: that would make consistent sense of how Haslanger puts things in different recent papers. Despite possible complications, I will speak of Haslanger as a refentialist, reserving further discussion of her precise view to footnotes.

${ }^{34}$ I use Williamson's terminology because I find it useful, and it has caught on. However, the label "inferentialism" is not perfect. In the relevant sense, Frege is supposed to be an inferentialist: Frege's senses cut more finely that reference. But Frege does not strictly focus on inferences.

${ }^{35}$ And for anyone who thinks this it might also be natural to go further and hold that whenever a concept's constitutive principles are immodest in the sense that they require something substantive of reality then the concept needs to be revised or replaced, even if what is required happens to be true. The supposed thought would be that substantive matters should not be settled conceptually. (Naturally, there is a question of how best to understand "substantive".) 
Haslanger's referentialism may seem to sit ill with some possible motivations for her proposed ameliorative analysis of 'woman'. Mark Richard (forthcoming) summarizes Haslanger's underlying thought as follows:

The, or an important, purpose of the concept woman is to subordinate people on the basis of their (perceived) female properties. We shouldn't be subordinating people on this basis; indeed, we should be fighting against such subordination. One way to do this is to reformulate the concept so that, so to speak, its noxious purpose is part of its definition. This will put the purposes for which the concept is actually being used front and center, allowing us to fight gender subordination. We should therefore understand what it is to be a woman as being someone who is systematically subordinated on the basis of (perceived) female properties. ${ }^{36}$

Richard's summary seems generally apt to me. But what does it mean for a referentialist to say that a purpose, or function, ${ }^{37}$ is part of the definition of a concept? If Haslanger were an inferentialist, at least of the psychological kind, then she could in principle say that it is part of competence with (her revised concept) 'woman' to have, or be disposed to have, certain beliefs about oppression; and the facts of oppression are in that way rendered salient by the concept. But given that all there is to the concept expressed by 'woman' is its intension there is no way that the descriptive information that Haslanger uses to describe the intension of the concept is itself part of the concept, or such that it is part of competence with the concept to believe or even know of the descriptive information in question. ${ }^{38}$

Actually, there are complications regarding the connection between concepts and the beliefs of concept users even given inferentialism. On prominent versions of inferentialism, the connection between concept possession and beliefs is complex. If constitutivity is spelled out in epistemic terms - a principle is constitutive of a concept if competence with the concept entails that one is entitled to believe the principle - then it doesn't follow from the fact that women are oppressed is constitutive of the concept WOMAN that anyone competent with the concept must believe that women are oppressed. And the most plausible version of the psychological view says only that competence with a concept involves having a disposition to believe the constitutive principles and not that competence involves actually believing these principles. In the background of the discussion of what is the best version of inferentialism are Timothy Williamson's arguments (see, e.g., his (2007)), to the effect that for every principle that can be regarded as concept-constitutive one can imagine users seemingly competent with the principle who do not believe the principle in question. The proposed versions of inferentialism are intended to get around Williamson's objections. ${ }^{39}$

It might be useful to compare Haslanger's proposal that the concept WOMAN should be revised with the different proposal that one should instill belief in the relevant sort of claim, without necessarily

\footnotetext{
36 [reference]

37 "Function" is arguably better in the context than Richard's "purpose".

38 Haslanger (forthcoming (b)) says that concepts are dispositions (see above, fn33), and given that view there is more to play with. Descriptive information can then be associated with the concept, by virtue of being the descriptive information that it is part of competence with the concept to accept. But even in her forthcoming (b), Haslanger repeats her point that there are no "core commitments" associated with words.

${ }^{39}$ When Haslanger says that there are no "core commitments" associated with words, what she holds is that there are no commitments that "cannot be overturned or negotiated". An inferentialist of the kind we are now considering can cheerfully agree.

In the context of her discussion, Haslanger's remark still seems to support a referentialist interpretation, since the alternative, positive picture she offers is one where "our utterances and our mental states do not have senses or concepts as their content "and what we believe are propositions, understood "as functions from possible circumstances to truth values, or equivalently, as sets of possible situations". (Haslanger forthcoming (a) [reference]; the latter passage Haslanger quotes from Stalnaker (1998), p. 343.)
} 
revising concepts. What about simply instilling beliefs to the effect that those people with observed or imagined bodily features presumed to be evidence of a female's biological role in reproduction tend to be systematically subordinated along some dimension (economic, political, legal, social, etc.), they are "marked" by the dominant ideology (in C) as a target for this treatment? This belief can, in principle, be salient independently of what concept one uses "woman" or any other label for. An opponent of the strategy of revising concepts can say that one should instead focus directly on beliefs like this. The project of revising concepts is of less importance. Of course, it can be that using Haslanger's concept can play an important role when it comes to instilling this belief and raising it to salience. It is not clear to me to what extent what I have called attention to is a problem for Haslanger: she may be perfectly fine with the claim that what is of main importance is beliefs and their salience, and concept change is just an indirect, fallible means to that end. Still it is worth stressing that the connection between on the one hand concepts used and, on the other, beliefs and their salience is by no means straightforward.

Let me also briefly consider how Scharp's project looks in light of the discussion of referentialism and inferentialism. Scharp's view is inconsistent with referentialism: since referentialism does not countenance constitutive principles, referentialism does not countenance inconsistent constitutive principles. And as earlier noted, Scharp favors a particular form of inferentialism. Inferentialism in either form discussed allows that there can be false and even inconsistent constitutive principles, and it can be thought that if some constitutive principles for a concept are false - or even inconsistent - then the concept in question must be revised. Conceptual engineering enters the stage. But the connection is not immediate or obvious. If competence required actual belief in constitutive principles the connection would be at least somewhat stronger: but what is so bad about being entitled to believe constitutive principles, or about merely having dispositions to believe these principles? ${ }^{40}$

\section{Concluding remarks}

My aim here has been to summarize some main theoretical issues regarding conceptual engineering. Some of my remarks have been critical. I have doubts about conceptual engineering as an (even near) unified philosophical project, and I have doubts about the philosophical significance of some questions that prominently have come up in connection with conceptual engineering.

But doubts about a unified philosophical project of conceptual engineering are compatible with enthusiasm about individual projects that concern conceptual engineering. Moreover, there is a distinction to be drawn. There is the prescriptive project of determining which concepts actually to employ, for such-and-such purposes, and the evaluative project of evaluating how good certain concepts are along different dimensions. Empirical issues arise most centrally in connection with the prescriptive projects. What are the actual consequences of employing this concept instead of that? How feasible is it to ensure that we employ a given concept rather than another? When it comes to the evaluative project, there are different kinds of evaluations. Some certainly turn on empirical issues. But many dimensions of evaluation are such that the evaluations need not turn on such issues. The evaluations can be independent of the questions about implementation.

Some of the doubts expressed have concerned the prescriptive project specifically; some more purely evaluative projects emerge relatively unscathed.

\footnotetext{
40 These remarks are also relevant to the issue raised above, $\mathrm{fn} 35$, of whether it is a defect in a concept if its constitutive principles require something substantive of reality. The intuitive argument against this stated above was that we might not want substantive matters to be settled conceptually. But given what is now stressed regarding constitutivity we can see that the talk of what is "settled" is misguided. Even if a principle is constitutive in the sense at issue, a thinker possessing the concept can come to reject it as untrue.
} 
The doubts should also be seen in light of the fact that in other ways I am very positively inclined toward the trend towards conceptual engineering. What concepts we use is important, and the concepts we have may not be the best concepts along all relevant dimensions or for all relevant purposes. Philosophy focusing only on our actual concepts and the things in the world they stand for threatens to be an unintentionally parochial enterprise.

\section{REFERENCES}

Blackburn, Simon: 1999, Think: A Compelling Introduction to Philosophy, Oxford University Press. Bolinger, Renee: 2017, "The Pragmatics of Slurs", Noûs 51: 439-62.

Brandom, Robert: 2001, "Modality, Normativity, and Intentionality", Philosophy and Phenomenological Research 63: 611-23.

Brandom, Robert: 2002, Tales of the Mighty Dead, Harvard University Press.

Burgess, Alexis: 2014, "Keeping 'True': A Case Study in Conceptual Ethics", Inquiry 57: 580-606.

Burgess, Alexis: forthcoming, "Never Say 'Never Say 'Never'”', in Burgess, Cappelen and Plunkett (forthcoming).

Burgess, Alexis, Herman Cappelen and David Plunkett (eds.): forthcoming, Conceptual Engineering and Conceptual Ethics, Oxford University Press.

Burgess, Alexis and David Plunkett: 2013, "Conceptual Ethics I", Philosophy Compass 8: 1091-101. Burgess, Alexis and David Plunkett: 2013a, "Conceptual Ethics II", Philosophy Compass 8: 1102-110. Cappelen, Herman: 2018, Fixing Language, Oxford University Press.

Carnap, Rudolf: 1950, The Logical Foundations of Probability, University of Chicago Press.

Catapang Podosky, Paul-Mikhail: forthcoming, "Ideology and Normativity: Constraints on Conceptual Engineering", Inquiry.

Chalmers, David: 2011, "Verbal Disputes", Philosophical Review 120: 515-66.

Creath, Richard (ed.): 1990, Dear Carnap, Dear Van, University of California Press.

Dever, Josh: forthcoming, "Preliminary Scouting Reports from the Outer Limits of Conceptual Engineering", in Burgess, Cappelen and Plunkett (forthcoming).

Dutilh Novaes, Catarina: forthcoming, "Carnapian Explication and Ameliorative Analysis: A Systematic Comparison", Synthese.

Eklund, Matti: 2015, "Intuitions, Conceptual Engineering, and Conceptual Fixed Points", in Chris Daly (ed.), The Palgrave Handbook of Philosophical Methods, Palgrave Macmillan, pp. 363-85.

Eklund, Matti: 2017, Choosing Normative Concepts, Oxford University Press.

Eklund, Matti: forthcoming, "Variance Theses in Ontology and Metaethics", in Burgess, Cappelen and Plunkett (forthcoming).

Ezcurdia, Maite: 1998, "The Concept-Conception Distinction", Philosophical Issues, Vol. 9, Concepts: 187-92.

Haslanger, Sally: 2000, "Gender and Race: (What) are They? (What) Do We Want Them To Be?", Noûs 34: 31-55.

Haslanger, Sally; 2006, "What Good are Our Intuitions? Philosophical Analysis and Social Kinds", Aristotelian Society Supplementary Volume 80: 89-118.

Haslanger, Sally: 2012, Resisting Reality: Social Construction and Social Critique, Oxford University Press.

Haslanger, Sally: forthcoming (a), "Going On, Not In the Same Way", in Burgess, Cappelen and Plunkett (forthcoming).

Haslanger, Sally: forthcoming (b), "How Not to Change the Subject", in Teresa Marques and Åsa Wikforss (eds.), Shifting Concepts, Oxford University Press.

Higginbotham, James: 1998, "Conceptual Competence", Philosophical Issues, Vol. 9, Concepts: 14962.

Jenkins, Katharine: 2016, "Amelioration and Inclusion: Gender Identity and the Concept of Woman", Ethics 126: 394-421.

Koch, Steffen: forthcoming, "The Externalist Challenge to Conceptual Engineering", Synthese. 
Ludlow, Peter: 2005, "Contextualism and the New Linguistic Turn in Epistemology", in Gerhard Preyer and Georg Peter (eds.), Contextualism in Philosophy: Knowledge, Meaning, and Truth, Oxford University Press, pp. 11-50.

Nietzsche, Friedrich. (1901/68). The Will to Power. Translated by Walter Kaufmann. Random House.

Nunberg, Geoffrey: 2018, "The Social Life of Slurs", in Daniel Fogal, Daniel Harris and Matt Moss (eds.), New Work on Speech Acts, Oxford University Press.

Plunkett, David and Herman Cappelen: forthcoming, "Conceptual Engineering and Conceptual Ethics: An Introduction", in Burgess, Cappelen and Plunkett (forthcoming).

Prinzing, Michael: 2018, "The Revisionist's Rubric: Conceptual Engineering and the Discontinuity Objection", Inquiry 61: 854-80.

Rabinowicz, Wlodek and Toni Rønnow-Rasmussen: 2004, "The Strike of the Demon: On Fitting ProAttitudes and Value", Ethics 114: 391-423.

Rawls, John: 1971, A Theory of Justice, Harvard University Press.

Quine, W.V.: 1960, Word and Object, MIT Press.

Richard, Mark: forthcoming, "The A-Project and the B-Project", in Burgess, Cappelen and Plunkett (forthcoming).

Scharp, Kevin: 2013, Replacing Truth, Oxford University Press.

Simion, Mona: 2018, "The 'Should' in Conceptual Engineering", Inquiry 61: 914-28.

Stalnaker, Robert: 1998, “What Might Nonconceptual Content Be?", Philosophical Issues 9: 339- 352.

Sterken, Rachel: forthcoming, "Amelioration and Meaning Change: Transformative Communicative Disruptions", in Burgess, Cappelen and Plunkett (forthcoming).

Strawson, P.F.: 1963, "Carnap's Views on Conceptual Systems Versus Natural Languages in Analytic Philosophy", in Paul Arthur Schilpp (ed.), The Philosophy of Rudolf Carnap, Open Court, pp. 50318.

Williamson, Timothy: 2007, The Philosophy of Philosophy, Blackwell.

Williamson, Timothy: 2009, "Reference, inference, and the Semantics of Pejoratives", in Joseph Almog and Paolo Leonardi (eds.), The Philosophy of David Kaplan. Oxford University Press, 13759. 